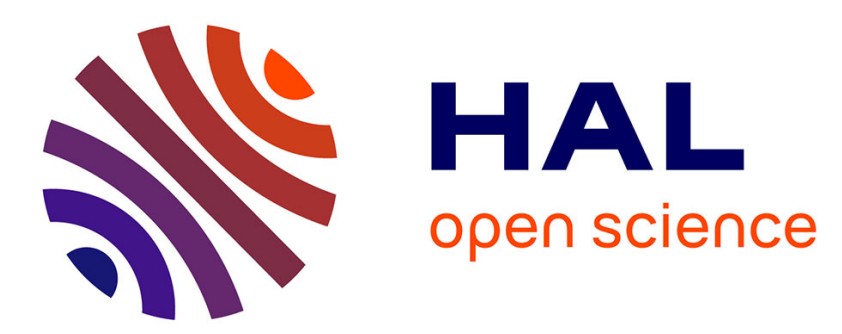

\title{
Enhancement of scattering and reflectance properties of plasma-sprayed alumina coatings by controlling the porosity
}

Jimmy Marthe, Erick Meillot, Gérard Jeandel, Franck Enguehard, J. Ilavsky

\section{- To cite this version:}

Jimmy Marthe, Erick Meillot, Gérard Jeandel, Franck Enguehard, J. Ilavsky. Enhancement of scattering and reflectance properties of plasma-sprayed alumina coatings by controlling the porosity. Surface and Coatings Technology, 2013, 220, pp.80-84. 10.1016/j.surfcoat.2012.05.048 . hal-00825549

\section{HAL Id: hal-00825549 \\ https://hal.science/hal-00825549}

Submitted on 24 May 2013

HAL is a multi-disciplinary open access archive for the deposit and dissemination of scientific research documents, whether they are published or not. The documents may come from teaching and research institutions in France or abroad, or from public or private research centers.
L'archive ouverte pluridisciplinaire HAL, est destinée au dépôt et à la diffusion de documents scientifiques de niveau recherche, publiés ou non, émanant des établissements d'enseignement et de recherche français ou étrangers, des laboratoires publics ou privés. 
Enhancement of scattering and reflectance properties of plasma-sprayed alumina coatings by controlling the porosity

\author{
J. MARTHE $^{1}$, E. MEILLOT ${ }^{1}$, G. JEANDEL ${ }^{2}$, F. ENGUEHARD ${ }^{3}$, J. ILAVSKY $^{4}$ \\ (1) CEA/DAM, Le Ripault, F-37260 Monts, France, +0033247344682, jimmy.marthe@cea.fr \\ (2) LEMTA, Av. de la forêt de Haye, BP 160, F-54504 Vandœuvre-lès-Nancy, France \\ (3) Ecole Centrale Paris, Laboratoire EM2C, UPR 288 ECP-CNRS, Grande Voie des Vignes, F- \\ 92295 Chatenay-Malabry, France \\ (4) Argonne National Laboratory, 9700S. Cass Avenue, bldg 434D, Argonne, IL 60439, USA
}

\begin{abstract}
The plasma-spraying process generates materials with typical, porous and complex, microstructures. Inspired by Dielectric Multilayer Mirrors (DMMs), thermal sprayed media may be used in the field of optics, particularly for making scattering and reflecting coatings suitable for a large range of wavelengths. In fact, pores inside plasma sprayed matrix create numerous optical index discontinuities, similarly to the gaps created in DMMs, in order to obtain high reflectivity.

The porosity of coatings microstructure can be customized by selection of plasma sprayed process parameters. This study aimed to optimize scattering and reflectance properties in porous alumina by the control of spray parameters resulting in the optimized porosity. A self-supporting bilayer with a diffuse reflectance over $90 \%$ over a large band of wavelengths was obtained.

The first layer (micro-structured), which is thick enough to support the free standing, was prepared by atmospheric plasma spraying (APS). The second layer (nanostructured) was manufactured by suspension plasma spraying (SPS) over the first layer in order to enhance the reflectance at short wavelengths.
\end{abstract}

\title{
Keywords
}

Alumina, Optical properties, Atmospheric plasma spraying, Suspension plasma spraying, Porosity, USAXS 


\section{Introduction}

The increasing use of reflecting optics in ultraviolet (UV), visible, and infrared (IR) devices has stimulated a great interest in research on coatings for mirrors [1]. A way to improve reflectivity is to manufacture multilayer materials with different optical indexes between successive layers [2]. This gap of optical index is also observed in heterogeneous materials, such as porous plasma sprayed coatings, between the matrix and the pore [3]. Therefore, with sufficient control of the main features of the porosity (value and main pore size), these coatings could be another way to provide reflecting coatings [4].

Thanks to their high damage resistance, even in extreme conditions, plasma sprayed ceramics should be suitable for manufacturing of optical devices for high power laser. The French high power laser project (Laser MégaJoule) plans to initiate a fusion reaction by laser confinement [5]. A key point of this project is to characterize the interaction between the laser and the plasma during the experiments. As the energy flux is locally highly concentrated, an idea is to use a precisely calibrated panel made of ceramic material which will scatter the radiation and consequently redirect only a part of it towards the detection cameras. The spectral range of operation is from $300 \mathrm{~nm}$ to $800 \mathrm{~nm}$.

Plasma-sprayed materials have typically heterogeneous, usually porous, microstructure. The porosity produces optical index gaps between the air within the pores and the matrix resulting from this volume scattering depends on the shape and the size of the heterogeneities [6]. In order to enhance the Mie scattering, the microstructure has to be suitable to the incident radiation and the pores size has to satisfy the following relationship:

$\mathrm{x}=\frac{\pi \times \operatorname{Re}\left(\mathrm{n}^{*}\right) \times \mathrm{d}}{\lambda_{0}} ; \ddot{\mathrm{O}}$

where $x$ is the size parameter, $n *$ the complex optical index of alumina, $d$ the average pore diameter and $\lambda o$ the wavelength of the incident radiation in vacuum. 
This equation shows that when the wavelength decreases, the pores sizes have to decrease too to conserve the size parameter. This relationship also allows us to estimate the approximate optimal pore sizes as function of wavelength to observe Mie diffusion as calculated in Table 1. With an incident radiation at $\lambda=300 \mathrm{~nm}$, the efficient pore sizes to provide Mie diffusion is about between 25 and $100 \mathrm{~nm}$; and at $\lambda=800 \mathrm{~nm}$, the pore sizes has to be between 100 and $300 \mathrm{~nm}$.

In this study, a self supporting bi-layer was manufactured by plasma spraying. Alumina was chosen for suitable optical properties, particularly its low absorption coefficient in the considered wavelengths range [7-8]. The first layer and its pores size distribution are specifically adapted for the higher wavelengths in the working range. The second nano-structured layer is manufactured by suspension plasma spraying over the first one in order to enhance optical properties at short wavelengths. This layer has much smaller pore size distribution to enhance Mie scattering at these short wavelengths.

\section{Experimental procedure}

\subsection{Coating preparation procedures}

As explained above, two techniques were used to produce the bi-layer system: Atmospheric Plasma Spraying and Suspension Plasma Spraying processes. Aluminium substrates $\left(25 \mathrm{~cm}^{2}\right.$ in surface and $2 \mathrm{~mm}$ thick) with an average roughness (Ra) of about $4 \mu \mathrm{m}$ and with a thermal expansion coefficient $\left(20 \times 10^{-6} \mathrm{~K}^{-1}\right)$ were chosen. The substrates were coated with fused alumina powder ($22+5 \mu \mathrm{m}$, H.C.Starck, Germany) for obtaining the microstructured layer. Next, the nanopowder (100 nm, Goodfellow, France) was mixed with distilled water, ultrasonically and mechanically stirred to break up the agglomerates. The concentration of the solid in the suspension was $10 \%$ in weight. No dispersant was added to the suspension since a sedimentation test showed that the sedimentation time was far higher than the spraying time. The suspension was injected into the plasma jet by using a mechanical feeder consisting of a pressurized reservoir in which the suspension is stored and forced through a precision nozzle ( $250 \mu \mathrm{m}$ in internal diameter) to provide the nano-structured part of the bi-layer system [9]. 
The two layers were manufactured with the same F4-VB plasma torch (Sulzer-Metco AG, Wohlen, Switzerland) equipped with $6 \mathrm{~mm}$ internal diameter nozzle. The operating parameters are summarized in Table 2 [10-11].

At the end of the process, the coatings were submerged in liquid nitrogen in order to create a thermal shock to separate the coatings from the substrates.

\subsection{Phase and microstructure analysis:}

The phase analyses were carried out by X Ray Diffraction (XRD) using a Siemens D501 diffractometer with the $\mathrm{Cu}-\mathrm{K} \alpha$ radiation $(\lambda=1.5406 \AA$ ) $)$ at an acquisition rate of $0.005 \%$ s.

The coating microstructures were observed by optical microscopy and with the Scanning Electron Microscope (SEM) XL30 (Koninklije Philips Electronics N.V., Amsterdam, The Netherlands) on polished and fractured cross sections.

The open porosities were determined by the hydrostatic pressure method.

Pores size distributions of microstructured coatings and of bi-layer coatings were measured by Mercury Intrusion Porosimetry (Micromeritics Autopore III 9410). The measurable pore sizes ranged between a few nanometers and $100 \mu \mathrm{m}$ by applying pressure from 0.04 up to $400 \mathrm{MPa}$ and assumed mercury wetting angle of $130^{\circ}$.

Pores microstructures of the coatings were also characterized by Ultra-Small Angle X-ray Scattering (USAXS) [12] to obtain quantitative pore size distributions for pores smaller than about 2 micrometers of the two layers following methods described in ref [13-14-15]. The experiment was conducted at the ChemMatCARS beamline 15-ID [16] at the Advanced Photon Source, Argonne National Laboratory. The instrument was using X-ray energy of $16.9 \mathrm{keV}$ to optimize the sample transmission and minimize effects of multiple scattering. Beam size was about $2 \mathrm{~mm}$ (width) $\mathrm{x} 0.8$ $\mathrm{mm}$ (height). Samples thickness was about $0.1 \mathrm{~mm}$, giving total scattering volume of sample characterized around $0.16 \mathrm{~mm}^{3}$. These samples were sprayed by APS and SPS separately, with the 
same parameters used to obtain the bi-layer system. The coatings were separated from the aluminum substrates by thermal shock. Data were analysed using Irena data analysis package [17].

\subsection{Optical properties}

The optical properties reflectance properties of the coatings were measured from $300 \mathrm{~nm}$ to $800 \mathrm{~nm}$ with the help of a UV-visible Varian Cary 5000 spectrometer (Varian Inc., Gloucester, Massachusetts, USA). The measurements were made on coatings removed from their substrates. As plasma sprayed coatings are highly scattering media, an integrating sphere was mounted to collect the reflected hemispherical flux. This sphere is made of a highly-reflecting inner coating $\left(\right.$ Spectralon $\left.^{\circledR}\right)$ so that the reflected light undergoes multiple reflections within the sphere and eventually reaches a detector mounted on the sphere. Spectralon ${ }^{\circledR}$ was used as a standard with $100 \%$ of reflectance.

\section{Results and discussions}

\subsection{Phases and microstructure analyses}

The XRD analyses (Figure 1) indicates that all alumina plasma sprayed coatings crystallize in a mixture of $\alpha$ and $\eta$ phases. The presence of the $\eta$ phase is due to the high thermal flux within the plasma, which causes the decomposition of alumina [18].

The observation by optical microscopy of the bi-layer material (Figure 2) shows a good adherence between the two layers. The micro-structured layer, which is manufactured by APS, has a typical porous microstructure of plasma-sprayed coatings. The thicknesses of the microstructured layer $(600 \mu \mathrm{m})$ and nanostructured layer $(90 \mu \mathrm{m})$ were chosen in order to optimize the reflectance properties. The SEM pictures of Figure 3 show the details of the microstructures of the two layers. The photomicrograph of the microstructured coating (Figure 3a) shows a lamellar structure with large size pores. For the nanostructured layer, the porosity has a globular form and the pores seem to be more numerous and smaller (Figure $3 b$ ). 
Mercury Intrusion Porosimetry was used to determine the pore size distribution of the microstructured layer alone and of the bi-layer system (Figure 4). For the micro-structured layer, a large band of pore sizes spreading from 80 to $400 \mathrm{~nm}$ and, centered at $200 \mathrm{~nm}$, is observed. This distribution shows also the presence of large pores with size between $500 \mathrm{~nm}$ to $3 \mu \mathrm{m}$. In reference to the Mie theory, this distribution seems to be adapted for providing high scattering with an incident radiation at $\lambda=800 \mathrm{~nm}$ (Table 1). For the bi-layer material, the same band is observed with a larger quantity of small pores in the range size below $80 \mathrm{~nm}$ due to the presence of the nanostructured layer. Two additional bands (at 20 and $40 \mathrm{~nm}$ ) in comparison with the distribution for microstructured coating are noticed. The Mie theory suggests that this distribution should improve scattering at shortest wavelengths (Table 1). The combination of the two layers causes high scattering in the global working range of wavelengths [300 nm; $800 \mathrm{~nm}$ ].

The USAXS analysis determined the pore size distribution of microstructured and nanostructured layers separately. Assuming model of spherical pores [14-15], it is possible to calculate the pore size distributions of the coatings (Figure 5) by measurement of the X-ray scattered intensity. The pore size volume distributions in the nanostructured layer are very different from ones in the microstructured layer (Figure 5a and 5b). The USAXS porosity of the micro-structured layer is only about $4.8 \%$ but estimated to be $13 \%$ by hydrostatic method. This difference is due to the fact that the SAXS technique is suitable measurements of nanopores (less than 2 microns in general) and does not detect the presence of large heterogeneities (pores over a few microns in size) in the microstructured coating. The low USAXS porosity shows that large pores are numerous in this coating as observed by Mercury Intrusion Porosimetry. Figure 5 presents in detail the volume of pores in several size ranges. The USAXS analysis confirms that the nanostructured layer contains more numerous and smaller pores than the microstructured coating, which should be able to enhance the scattering and consequently the reflectance at short wavelengths.

\subsection{Reflectance properties}


The reflectance measurements of the microstructured coating and the bi-layer system were performed in order to observe the influence of the nanostructured layer (Figure 6). For the microstructured coating alone, the reflectivity can be considered to be constant between $500 \mathrm{~nm}$ and $800 \mathrm{~nm}$ with a satisfying value close to $90 \%$ in this range. Below $500 \mathrm{~nm}$, the reflectance decreases with the wavelengths. As predicted by the Mie theory, the pore size in this coating is too large to scatter efficiently the incident radiation at short wavelengths. With the addition of the nanostructured layer, the decrease in reflectance for the short wavelengths is less important. In fact, the microstructure characterization of this layer made previously shows that pores in this coating are more able to scatter the incident radiation. Nevertheless, a slow decrease in reflectance is still observed and can be attributed to the increase in absorption of alumina below $\lambda_{0}=400 \mathrm{~nm}$. At higher wavelengths (above $600 \mathrm{~nm}$ ), the influence of the nano-structured layer is not observed anymore because the nanopores become too small to scatter radiation efficiently. As the absorption coefficient of alumina is very low in this range of wavelengths, the incident radiation goes right through the nanostructured layer and reaches the microstructured, so that scattering in the same as the microstructured coating alone.

\section{Conclusions}

This work shows the potential of plasma spray processes to be used to manufacture scattering and reflecting coatings. In the UV-visible range of wavelengths, the optimization of the pore size distribution within the material improves the reflectance properties.

An alumina bi-layer material, which is manufactured successively by APS and SPS, exhibits high scattered reflectance (>90\%) between 300 and $800 \mathrm{~nm}$. The micro-structured layer allows the manufacturing of a self-supporting coating with sufficient mechanical properties. The pore size distribution of this layer, which is centered around $200 \mathrm{~nm}$, permits to scatter radiation efficiently only the highest wavelengths of the range under study (between 500 and $800 \mathrm{~nm}$ ). The scattering at 
the lowest wavelengths (ie between 300 and $500 \mathrm{~nm}$ ) is provided by the nanostructured coating with smaller pores (below $80 \mathrm{~nm}$ in size) sprayed over the first one.

\section{Acknowledgments}

ChemMatCARS Sector 15 is principally supported by the National Science Foundation/Department of Energy under grant number NSF/CHE-0822838. Use of the Advanced Photon Source was supported by the U.S. Department of Energy, Office of Science, Office of Basic Energy Sciences, under Contract No DE-AC02-06CH11357.

\section{References}

[1] G. Haas, Reflectance and preparation of front-surface mirrors for use at various angles of incidence from the ultraviolet to the far infrared, J. Opt. Soc. Am, Vol. 72, 1982, p27-39

[2] T. Sakaguchi, A. Katsube, T. Honda, F. Koyama, K. Iga, MgO/Si02 Dielectric Multilayer Reflectors for GaN- based Ultra-violet Surface Emitting Lasers, Lasers and ElectroOptics Society $1995, \mathrm{p} 102$

[3] P. Fauchais, G. Montavon, and G. Bertrand, From Powders to Thermally Sprayed Coatings, Journal of Thermal Spray Technology, 2010, Vol. 19, p56-80

[4] O. Rozenbaum, D. De Souza Meneses, P. Echegut, Texture et porosity effects on thermal radiative behavior of alumina ceramics, Int. J. Thermophys., 2009, p580-590

[5] N. Fleurot, C. Cavailler, J.L. Bourgade, The Laser Mégajoule (LMJ) Project dedicated to inertial confinement fusion: Development and construction status, Fusion Engineering and Design 74 (2005), p147-154

[6] M. F. Modest, Radiative Heat Transfer, Mc Graw-Hill Edition, New York, 1993, Chap 10

[7] E. D. Palik, Handbook of Optical constants of Solids III, p653-682

[8] Alumina as a ceramic material, The American ceramic Society, Special Publication No.4, p90

[9] K Wittmann-Ténèze, K. Vallé, L. Bianchi, F. Blein, P. Belleville, , Nanostructured Coating and Coating Process, Fr patent n ${ }^{\circ} 0452390$ (2004), CEA Le Ripault, France. 
[10] V. Debout, A. Vardelle, P. Abélard, P. Fauchais, Optical Properties of Yttria-Stabilized Zirconia Plasma-Sprayed Coatings, Journal of Thermal Spray technology, 2006, p525-600

[11] Y. Zeng, S. W. Lee, C. X. Ding, Plasma spray coating in different nanosize alumina, Materials letters, $57, \mathrm{p} 495-501$

[12] J. Ilavsky, P. R. Jemian, A. J. Allen, F. Zhang, L. E. Levine, and Gabrielle G. Long, Ultrasmall-angle X-ray scattering at the advanced Photon Source, J. Appl. Crystallogr. 42 (3), 2009, p469-479

[13] J. Ilavsky, Characterization of Complex Thermal Barrier Deposits Pore Microstructures by a combination of Imagine, Scattering and Intrusion Techniques, J. Therm. Spray Technol. 19(1-2), 2010, p178-189

[14] A. Bacciochini, G. Montavon, J. Ilavsky, A. Denoirjean, P. Fauchais, Porous Architecture of SPS Thick YSZ Coatings Structured at the Nanometer Scale ( $\sim 50 \mathrm{~nm})$, J. Therm. Spray Technol. 19 (1), 2010, 198-206

[15] A. Bacciochini, F. Ben-Ettouil, E. Brousse, J. Ilavsky, G. Montavon, A. Denoirjean, S. Valette, P. Fauchais, Quantification of voids networks of as-sprayed and annealed nanostructured yttria-stabilized zirconia (YSZ) deposits manufactured by suspension plasma spraying, "Surf. Coat. Technol. 205 (3) , 2010, p 683-689

[16] http://cars9.uchicago.edu/chemmat/index.html

[17] J. Ilavsky, P. R. Jemian, Irena: tool suite for modelling and analysis of small-angle scattering, J. Appl. Crystallogr., 42 (2), 2009

[18] R. J. Damani, P. Makroczy, Heat treatment induced phase and microstructural development in bulk plasma sprayed alumina, J. Eu. Ceram. Soc., 2000, 20, p 867-888 
Table 1 : Values of calculated diameters $d$ of pores according Mie parameter and incident wavelength

\begin{tabular}{|c|c|c|c|}
\cline { 2 - 4 } \multicolumn{1}{c|}{} & $\mathbf{x}=\mathbf{0 . 5}$ & $\mathbf{x}=\mathbf{1}$ & $\mathbf{x}=\mathbf{2}$ \\
\hline $\boldsymbol{\lambda}=\mathbf{3 0 0} \mathbf{~ n m}$ & $26 \mathrm{~nm}$ & $53 \mathrm{~nm}$ & $106 \mathrm{~nm}$ \\
\hline $\boldsymbol{\lambda}=\mathbf{8 0 0} \mathbf{~ n m}$ & $70 \mathrm{~nm}$ & $140 \mathrm{~nm}$ & $282 \mathrm{~nm}$ \\
\hline
\end{tabular}


Table 2 : Plasma sprayed experimental setup for the microstructured layer and the nanostructured layer

\begin{tabular}{|c|c|c|}
\cline { 2 - 3 } \multicolumn{1}{c|}{} & APS & SPS \\
\hline Ar flow rate (SLPM) & 12 & 40 \\
\hline He flow rate (SLPM) & 45 & 0 \\
\hline H $_{\mathbf{2}}$ flow rate (SLPM) & 3 & 10 \\
\hline Current (A) & 500 & 600 \\
\hline Voltage (V) $_{\text {Spray distance (mm) }}(\mathbf{m})$ & 68 \\
\hline Gun traverse speed (m.s & $\mathbf{- 1}$ ) & \multicolumn{2}{|c|}{1.5} \\
\hline Feeding rate (g/min) & 20 & 40 \\
\hline Pressure injection (bar) & - & 3 \\
\hline
\end{tabular}




\section{List of figures}

Figure 1: XRD pattern of plasma sprayed alumina coatings

Figure 2: Optical microscopies of bi-layer system : global view (2a) and interlayer view (2b)

Figure 3: Microstructure of fractured sections of microstructured (3a) and nanostructured (3b) plasma sprayed alumina coatings

Figure 4: Pores size distributions of microstructured (4a) and bi-layer (4b) coatings measured by Mercury Intrusion Porosimetry

Figure 5: Pores size distributions of microstructured and nanostructured layers measured by SAXS Figure 6: Influence of the nanostructured layer on reflectivity 


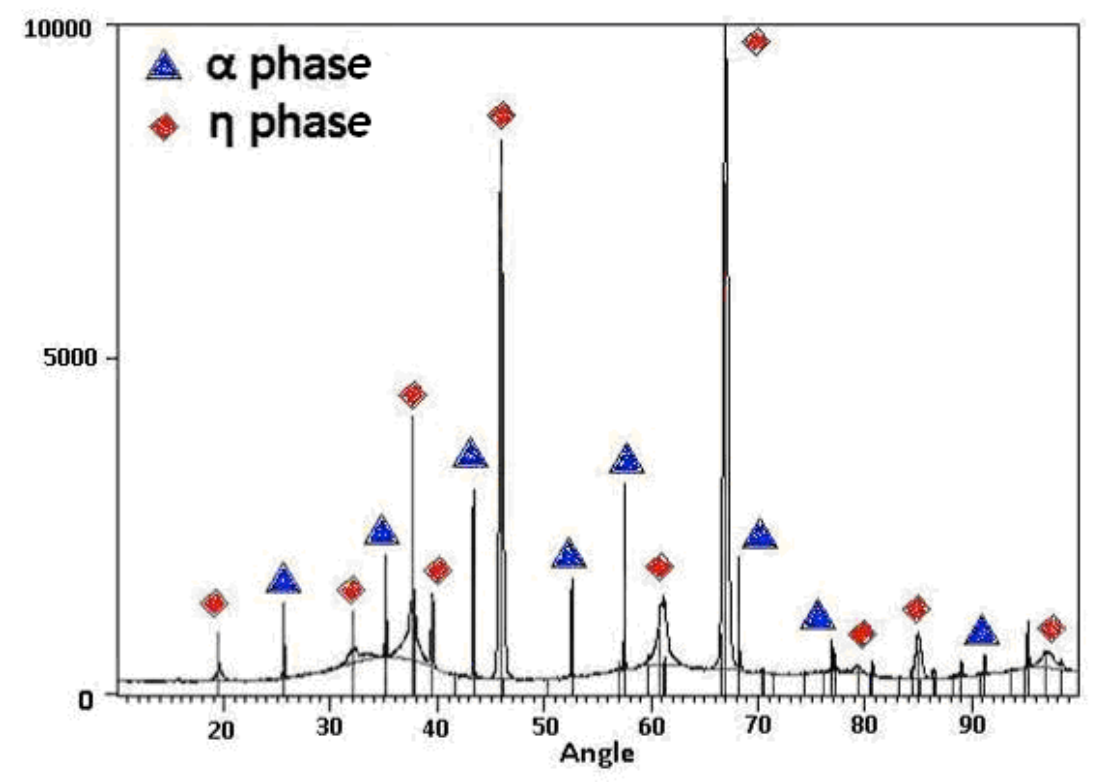

Figure 1 
a)

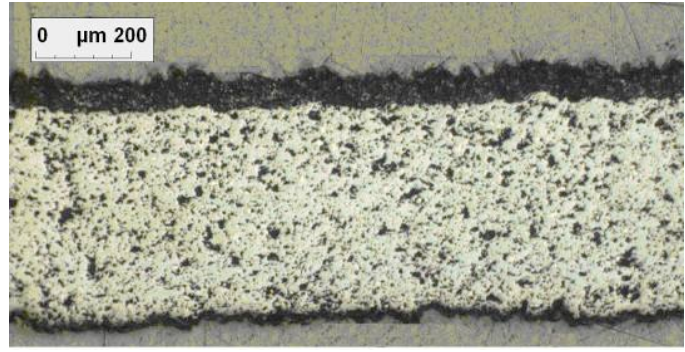

b)

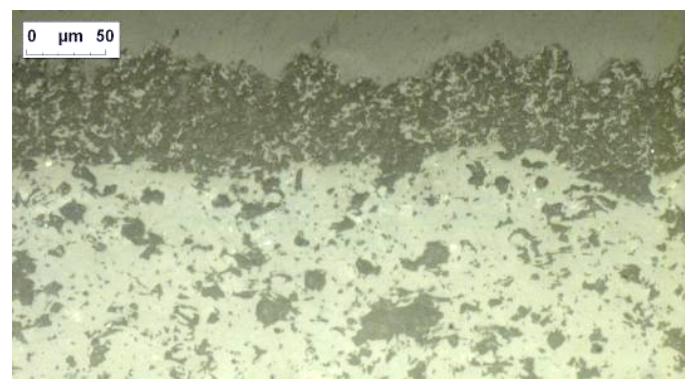

Figure 2 

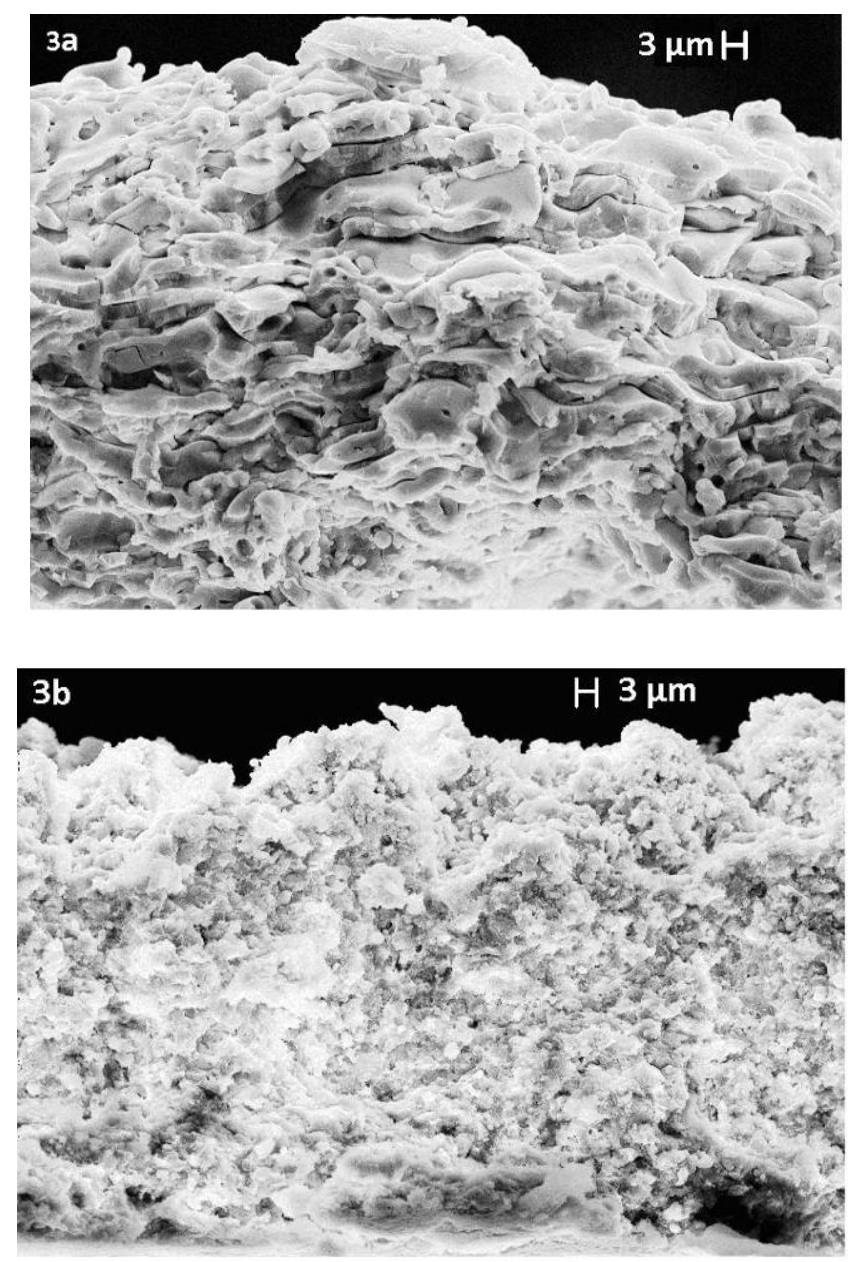

Figure 3 

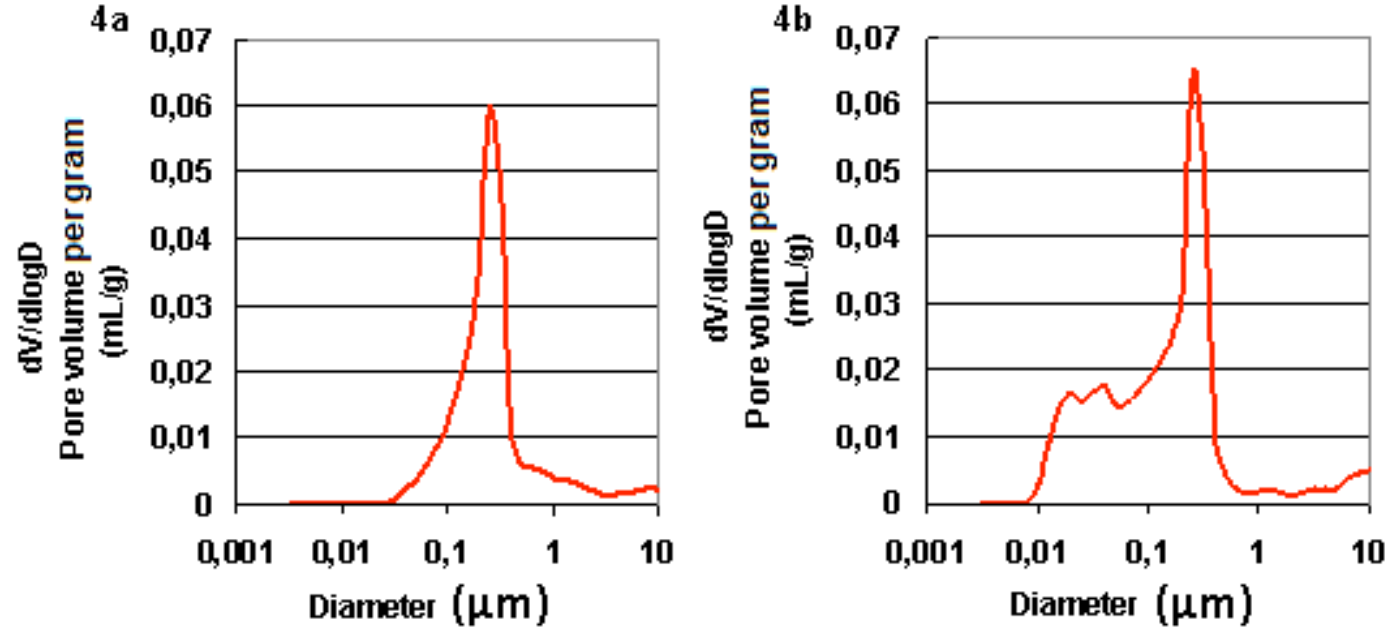

Figure 4 

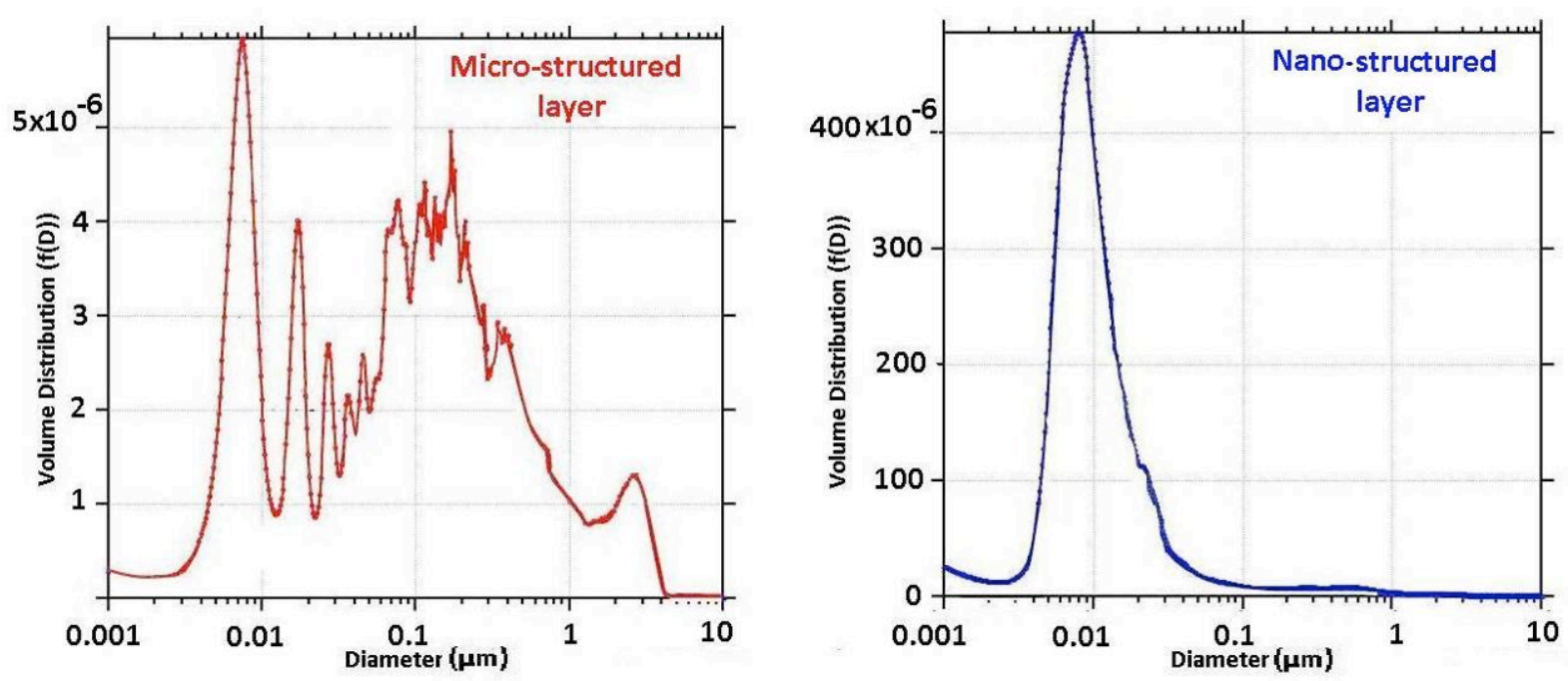

\begin{tabular}{|c|c|c|c|c|c|}
\cline { 2 - 6 } \multicolumn{1}{c|}{} & USAXS & \multicolumn{3}{|c|}{ Fraction of total porosity in different size ranges } \\
\cline { 3 - 6 } & $\begin{array}{c}\text { Total } \\
\text { Porosity }\end{array}$ & $0,001-0,01 \mu \mathrm{m}$ & $0,01-0,1 \mu \mathrm{m}$ & $0,1-1 \mu \mathrm{m}$ & $1-10 \mu \mathrm{m}$ \\
\hline $\begin{array}{c}\text { Microstructured } \\
\text { coating }\end{array}$ & $4.8 \%$ & $0.4 \%$ & $5 \%$ & $42 \%$ & $52.6 \%$ \\
\hline $\begin{array}{c}\text { Nanostructured } \\
\text { coating }\end{array}$ & $14.5 \%$ & $15.3 \%$ & $25.3 \%$ & $32.2 \%$ & $27.2 \%$ \\
\hline
\end{tabular}

Figure 5 


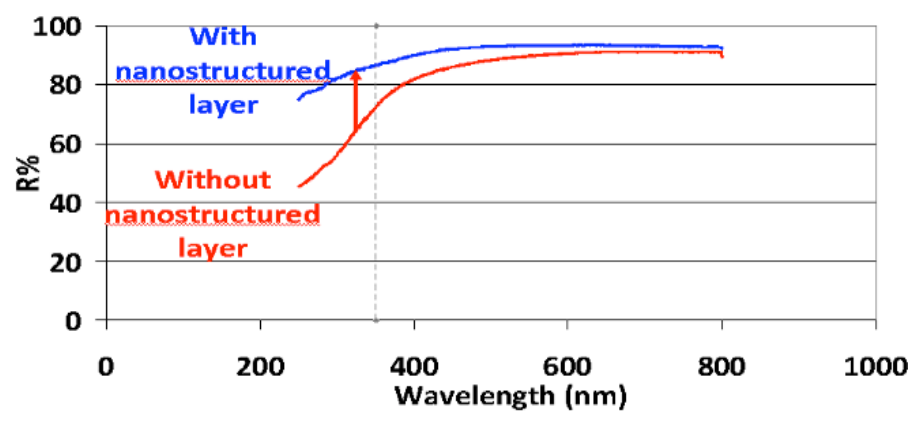

Figure 6 